\title{
Zfat expression in ZsGreen reporter gene knock-in mice: Implications for a novel function of Zfat in definitive erythropoiesis
}

\author{
TOSHIYUKI TSUNODA ${ }^{1,2^{*}}$, KEIKO DOI ${ }^{1,2^{*}}$, SHUHEI ISHIKURA ${ }^{1,2^{*}}$, \\ HAO LUO $^{1}$, KENSUKE NISHI ${ }^{1}$, HIROSHI MATSUZAKI ${ }^{1}$, MIDORI KOYANAGI ${ }^{1}$, \\ YOKO TANAKA $^{1}$, TADASHI OKAMURA ${ }^{3,4}$ and SENJI SHIRASAWA ${ }^{1,2}$
}

\author{
${ }^{1}$ Department of Cell Biology, Faculty of Medicine; ${ }^{2}$ Central Research Institute for Advanced Molecular Medicine, \\ Fukuoka University, Fukuoka 814-0180; ${ }^{3}$ Department of Laboratory Animal Medicine; ${ }^{4}$ Section of Animal Models, \\ Department of Infectious Diseases, Research Institute, National Center for Global Health and Medicine, Tokyo 162-8655, Japan
}

Received January 24, 2018; Accepted August 2, 2018

DOI: $10.3892 / \mathrm{ijmm} .2018 .3806$

\begin{abstract}
Zinc finger and AT-hook domain containing (Zfat) is a transcriptional regulator harboring an AT-hook domain and 18 repeats of a $\mathrm{C} 2 \mathrm{H} 2$ zinc-finger motif, which binds directly to the proximal region of transcription start sites in Zfat-target genes. It was previously reported that deletion of the Zfat gene in mice yields embryonic lethality by embryonic day 8.5 and impairs primitive hematopoiesis in yolk sac blood islands. In addition, Zfat has been reported to be involved in thymic T-cell development and peripheral T-cell homeostasis. In the present study, in order to obtain a precise understanding of the expression and function of Zfat, a knock-in mouse strain $\left(Z f a t^{\mathrm{ZsG} /+}\right.$ mice), which expressed ZsGreen in the Zfat locus, was established. ZsGreen signals in tissues and cells of $Z \mathrm{fat}^{\mathrm{ZsG} /+}$ mice were examined by flow cytometric and histological analyses. Consistent with our previous studies, ZsGreen signals in $\mathrm{Zfat}^{\mathrm{ZsG} /+}$ mice were detected in the embryo and yolk sac blood islands, as well as in thymocytes, B and T cells.

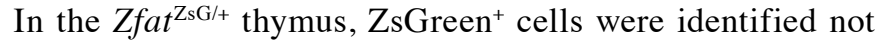
only in T-cell populations but also in thymic epithelial cells, suggesting the role of Zfat in antigen-presenting cells during thymic T-cell development. ZsGreen signals were observed in definitive erythroid progenitor cells in the fetal liver and adult bone marrow of $\mathrm{Zfat}^{\mathrm{ZsG} /+}$ mice. The proportion of $\mathrm{ZsGreen}^{+}$ cells in these tissues was highest at the early stage of erythroid differentiation, suggesting that Zfat serves particular roles in definitive erythropoiesis. Histological studies demonstrated
\end{abstract}

Correspondence to: Professor Senji Shirasawa, Department of Cell Biology, Faculty of Medicine, Fukuoka University, 7-45-1 Nanakuma, Jonan-ku, Fukuoka 814-0180, Japan

E-mail: sshirasa@fukuoka-u.ac.jp

*Contributed equally

Key words: Zfat, knock-in mouse, definitive erythropoiesis that ZsGreen signals were detected in the pyramidal cells in the hippocampal CA1 region and the Purkinje cells in the cerebellum, suggesting novel functions of Zfat in nervous tissues. Taken together, these results indicated that the $Z \mathrm{fat}^{\mathrm{ZsG} /+}$ reporter mouse may be considered a useful tool for elucidating the expression and function of Zfat.

\section{Introduction}

Zinc finger and AT-hook domain containing (Zfat) is a transcriptional regulator that contains 18 zinc-finger domains and one AT-hook domain $(1,2)$. Zfat regulates the transcription of the Zfat target genes by binding directly to the proximal region of transcription start sites (1). From the evolutionary point of view, Zfat is highly conserved from fish to humans, and is considered an essential molecule in development and cellular differentiation (3).

Zfat was originally identified as a candidate susceptibility gene for autoimmune thyroid disease (4). Previous studies have reported that genetic variants of $Z$ fat are strongly associated with interferon- $\beta$ therapy responsiveness in multiple sclerosis (5), Hashimoto disease severity (6) and the susceptibility of pigs to enterotoxigenic Escherichia coli infection (7). Genetic variants of Zfat have also been reported to be associated with non-immune-associated diseases, including cerebral aneurysms (8), hypertension (9) and cancer (10). Furthermore, genome-wide association studies have revealed that genetic variants of Zfat affect adult height in Japanese and Korean populations $(11,12)$, and horse body size $(13,14)$. These findings indicated that Zfat may have critical roles in particular human diseases and development, as well as in immune-related cells.

In mice, Zfat is expressed during embryonic development, and in adult tissues, such as the spleen and thymus $(3,15)$. Zfat-deficient $\left(Z \mathrm{fat}^{-/}\right)$mice exhibit embryonic lethality and severe defects in the differentiation of hematopoietic progenitor cells in yolk sac blood islands, thus indicating that Zfat serves a critical role in primitive hematopoiesis (15). Our previous studies reported that Zfat gene ablation in thymic $\mathrm{T}$ cells in $Z \mathrm{fat}^{\mathrm{f} / \mathrm{f}}-$ LckCre mice induces a marked decrease 
in the number of cluster of differentiation $(\mathrm{CD}) 4^{+} \mathrm{CD} 8^{+}$ double-positive (DP) cells, alongside impaired positive selection and excessive apoptosis $(16,17)$. Furthermore, Zfat deficiency in peripheral $\mathrm{T}$ cells in $\mathrm{Zfat} \mathrm{f}^{\mathrm{ff}}-\mathrm{CD} 4 \mathrm{Cre}$ mice results in a decrease in peripheral $\mathrm{T}$ cells, as well as decreased expression of interleukin-7R $\alpha$ (18) and forkhead box O1 (19), thus indicating that Zfat is an essential molecule associated with thymic and peripheral $\mathrm{T}$ cells. However, the detailed pattern of Zfat expression during embryonic development and in adult tissues remains to be elucidated.

The present study established a knock-in reporter mouse strain $\left(Z f a t Z^{\mathrm{sG} /+}\right.$ mice), which expressed a green fluorescent protein, ZsGreen, in the Zfat locus. Using this reporter mouse, ZsGreen signals were examined during development and in various adult tissues, leading to elucidation of the pattern of Zfat expression. The present findings may have implications for the novel functions of Zfat in thymic epithelial cells (TECs) and definitive erythropoiesis in the fetal liver and bone marrow.

\section{Materials and methods}

Generation of Zfat-ZsGreen reporter mice. All animal experiments were approved by the Animal Care and Use Committee of the National Center for Global Health and Medicine (NCGM) Research Institute (NCGM\#14032; Tokyo, Japan) and the Institutional Animal Care and Use Committee of Fukuoka University (Fukudai\#157; Fukuoka, Japan). The present study was approved by the ethics committee of Fukuoka University (Fukudai\#372). All mice were maintained in a temperature-controlled $\left(23^{\circ} \mathrm{C}\right)$ facility under a 12 -h light/dark cycle with free access to water and standard rodent chow. Between five and 10 mice were kept in one cage $\left(500 \mathrm{~cm}^{2}\right)$. All mice (17-35 g) were sacrificed by cervical dislocation under standard anesthetized conditions using isoflurane or carbon dioxide, and tissues were removed for further analysis.

To construct a ZsGreen-FRT-pGKneo-FRT cassette, ZsGreen cDNA was amplified by polymerase chain reaction (PCR) from the pIRES2-ZsGreen1 vector (Clontech Laboratories, Mountainview, CA, USA) using KOD-Plus-Neo DNA polymerase (Toyobo Life Science, Osaka, Japan) and the following primers: Forward primer, 5'-ATGGCC CAGTCCAAGCACGGCC-3' and reverse primer, 5'-TCA GGGCAAGGCGGAGCCG-3'. PCR products were inserted at cloning sites upstream of the FRT-pGKneo-FRT cassette in the pPE7neoW-F2LR vector (provided by Dr Kiyoshi Takeda, Laboratory of Immune Regulation, Graduate School of Medicine, Osaka University, Osaka, Japan). The ZsGreen-FRT-pGKneo-FRT cassette was inserted at the ATG translational start site of the Z fat gene in-frame in the bacterial artificial chromosome (BAC) clone (clone number, RP23-57E24; DNAFORM, Yokohama, Japan) using the pRed/ET recombination kit (Gene Bridges GmbH, Heidelberg, Germany), in accordance with the manufacturer's protocol. To construct the targeting vector, a $22.5-\mathrm{kb}$ fragment, which consisted of the ZsGreen-FRT-pGKneo-FRT cassette, $19 \mathrm{~kb}$ of a $5^{\prime}$ homology arm and $1 \mathrm{~kb}$ of a $3^{\prime}$ homology arm, was retrieved from the BAC clone and inserted into a minimal vector carrying a ColE1 origin plus ampicillin-resistant gene (Gene Bridges $\mathrm{GmbH}$ ) using the pRed/ET recombination kit.
The targeting vector was linearized by SalI and electroporated into TT2 embryonic stem (ES) cells (RIKEN BioResource Center, Tsukuba, Japan), as described previously (20). To select mutant ES cells, cells were cultured on embryonic fibroblast feeder cells (Cell Biolabs, Inc., San Diego, CA, USA) in the presence of $350 \mu \mathrm{g} / \mathrm{ml} \mathrm{G} 418$ (Thermo Fisher Scientific, Inc., Waltham, MA, USA). To identify mutant ES cell clones, genomic DNA was extracted from ES cells and subjected to genotyping analysis by Southern blotting and PCR. Mutant ES cells were microinjected into the blastocysts of ICR mice (Japan SLC, Inc., Hamamatsu, Japan), as described previously (20). One 8-week-old male chimera ( $\mathrm{fat}^{\mathrm{ZsG} \text {-neo/+ }}$ mouse) was mated with two 8-week-old FLPe deleter mice [B6-Tg(CAG-FLPe)36; RIKEN BioResource Centre] to eliminate the pGKneo cassette and to generate $\mathrm{Zfat}^{\mathrm{ZsG} /+}$ mice. To identify the $\mathrm{Zfat}{ }^{\mathrm{ZsG} /+}$ mice, genomic DNA was extracted from the mouse tail and subjected to genotyping analysis by Southern blotting and PCR. Z $f_{a t} \mathrm{Z}_{\mathrm{sG} /+}$ mice were backcrossed with three 8-week-old C57BL/6 mice (weight, 23-28 g; Charles River Laboratories Japan, Inc., Yokohama, Japan) six times in order to maintain the genetic background of C57BL/6 mice.

Genotyping by Southern blotting and PCR. For Southern blotting, genomic DNA was extracted using Wizard ${ }^{\circledR}$ Genomic DNA Purification kit (Promega Japan, Tokyo, Japan). A total of $25 \mu \mathrm{g}$ of DNA was digested with $B g l \mathrm{II}$, separated by $0.8 \%$ agarose gel electrophoresis and transferred to a Biodyne B nylon membrane (Thermo Fisher Scientific, Inc.). Membranes were prehybridized for $1 \mathrm{~h}$ at $42^{\circ} \mathrm{C}$ in hybridization buffer $(50 \%$ formamide, 20\% SDS, $1 \mathrm{M} \mathrm{Na}_{2} \mathrm{HPO}_{4}, 0.5 \mathrm{M}$ EDTA and $3 \mathrm{M}$ $\mathrm{NaCl}$. Subsequently, hybridization was conducted for $16 \mathrm{~h}$ at $42^{\circ} \mathrm{C}$ in the hybridization buffer containing ${ }^{32} \mathrm{P}$-radiolabeled probes. After hybridization, the membranes were washed twice in $2 \mathrm{X}$ saline-sodium citrate (SSC) at room temperature for $5 \mathrm{~min}$, in $1 \mathrm{X} \mathrm{SSC} / 0.1 \% \mathrm{SDS}$ at $42^{\circ} \mathrm{C}$ for $20 \mathrm{~min}$, and then in $1 \mathrm{X} \mathrm{SSC} / 0.1 \% \mathrm{SDS}$ at $45^{\circ} \mathrm{C}$ for $10 \mathrm{~min}$. Hybridized membranes were exposed to BIOMAX MR film (Carestream Health, Inc., Rochester, NY, USA) for 3-4 days at $-70^{\circ} \mathrm{C}$ with BIOMAX MS intensifying screen (Carestream Health, Inc.).

DNA fragments used to prepare the external probe were amplified by PCR from mouse genomic DNA using the following primers: Forward primer, 5'-GGGTGCAAAGGT TTCTGCTTC-3' and reverse primer, 5'-AAAGCAAATGCA TGGTGACA-3'. DNA fragments used to prepare the ZsGreen probe were amplified by PCR from the pIRES2-ZsGreen1 plasmid DNA using the following primers: Forward primer, 5'-ATGGCCCAGTCCAAGCACGGCC-3' and reverse primer, 5'-TCAGGGCAAGGCGGAGCCG-3'. PCR products were radiolabeled with ${ }^{32} \mathrm{P}$ using High Prime kit (Merck, Kenilworth, NJ, USA). BglII digestion of genomic DNA identified a 9.8-kb ZsGreen-FRT-pGKneo-FRT recombinant allele, a 8.3-kb pGKneo cassette-deleted recombinant allele and a 7.2-kb wild-type (WT) allele, when hybridized with the external probe. The ZsGreen probe was used to confirm homologous recombination and ensure that there was only one integration site.

For PCR genotyping analysis, genomic DNA was extracted from mouse tails by incubating samples in $50 \mathrm{mM} \mathrm{NaOH}$ at $95^{\circ} \mathrm{C}$ for $10 \mathrm{~min}$; the samples were then mixed with $1 \mathrm{M}$ 
A
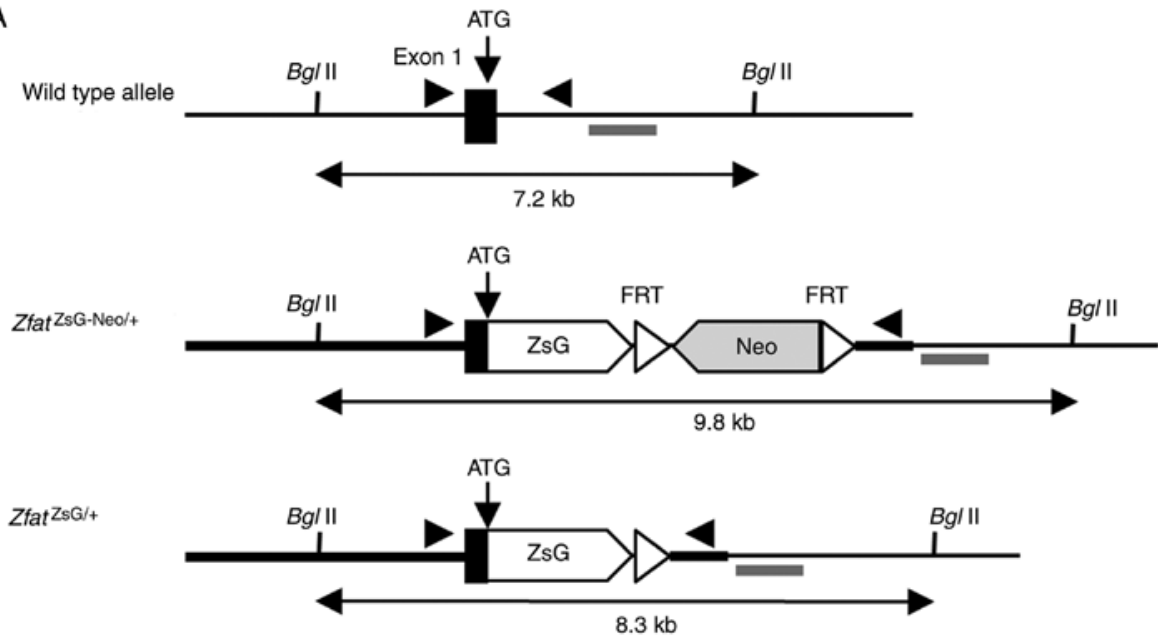

B
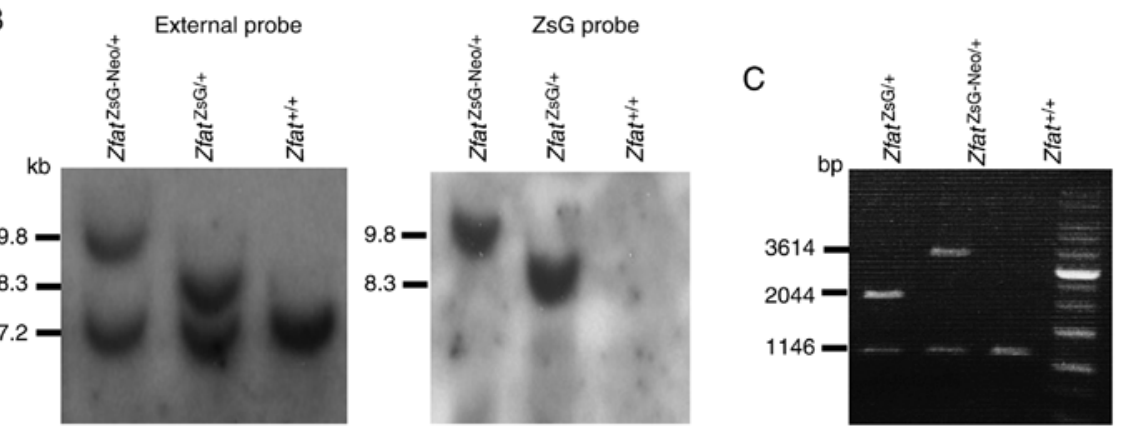

Figure 1. Generation of Zfat-ZsGreen knock-in reporter mice. (A) Targeted knock-in of the ZsGreen gene at the ATG translational start site of the Zfat gene. The locations of the Southern blot probe (gray bar) and PCR primers (arrowheads) are shown. (B) Southern blotting of $B g l \mathrm{lI}$-digested DNA using the external (left) or ZsGreen (right) probe. (C) PCR-based genotyping of the $\mathrm{Zfat}^{\mathrm{ZSG} /+}, \mathrm{Zfat}^{\mathrm{ZsG}-\mathrm{Neo} /+}$ and $\mathrm{Zfat} t^{+/+}$mice. Data are representative of three independent experiments. FRT, FLPe recombinase recognition sites; Neo, pGKneo selection cassette; PCR, polymerase chain reaction; Zfat, zinc finger and AT-hook domain containing; ZsG, ZsGreen.

Tris- $\mathrm{HCl}(\mathrm{pH}$ 8.0) for neutralization. PCR was performed for 26 cycles at $98^{\circ} \mathrm{C}$ for $10 \mathrm{sec}$ and $68^{\circ} \mathrm{C}$ for 3 min using KOD FX Neo DNA polymerase (Toyobo Life Science) and the following primers: Forward primer, 5'-GATGTGCGAGGC ACTGTCACTTCC-3' and reverse primer, 5'-TGGCCGCTC CCTCTGAAGGTCACTAG-3'. PCR products were analyzed by $0.8 \%$ agarose gel electrophoresis.

Histological examination. Embryos with yolk sacs were obtained by sacrificing pregnant $\mathrm{Zfat}^{\mathrm{ZsG} /+}$ mice at embryonic day (E)9.5 or 10.0, were fixed in $10 \%$ neutral-buffered formalin solution (Wako Pure Chemical Industries, Osaka, Japan) for $24 \mathrm{~h}$ at $4^{\circ} \mathrm{C}$ and then embedded in paraffin. Samples were cut into $3 \mu \mathrm{m}$ sections and were then stained with hematoxylin and eosin (H\&E) using the Cryosection preparation kit (1) (Section-lab Co., Ltd., Hiroshima, Japan), in accordance with the manufacturer's protocol. To prepare cryosections from brain and placenta samples of 4-8-week-old mice and 8-12-week-old pregnant mice, respectively, tissues were fixed in $10 \%$ neutral-buffered formalin solution for $24 \mathrm{~h}$ at $4^{\circ} \mathrm{C}$, embedded in super cryo-embedding medium (SCEM) and then frozen in accordance with methods described by Kawamoto and Kawamoto (21). The SCEM-embedded frozen tissues were cut into $6 \mu \mathrm{m}$ sections, and adjacent sections were processed for fluorescence microscopy or H\&E staining. All fluorescence and bright field images were obtained using a Biorevo BZ-9000 inverted-phase microscope (Keyence Corporation, Osaka, Japan).

Flow cytometry. To prepare single-cell suspensions from cerebrum, cerebellum, testis, retina, lung and liver samples of 4-10-week-old mice, tissues were minced in PBS and then incubated in Cell Dissociation Buffer (Thermo Fisher Scientific, Inc.) for $10-30 \mathrm{~min}$ at $37^{\circ} \mathrm{C}$. To prepare single-cell suspensions from spleen and thymus of 4-8-week-old mice, the lymphoid organs were gently ground by pressing the tissues between frosted-glass slides. To prepare single-cell suspensions from bone marrow, tibias and femurs were dissected from 4-10-week-old mice, the ends of the bones were cut, and marrow was flushed out with PBS using a needle and syringe. Fetal livers were obtained by sacrificing pregnant mice at E12.5. To prepare single-cell suspensions from fetal liver, the tissues were gently ground by pressing between frosted-glass slides. Cell suspensions were filtered through a $100-\mu \mathrm{m}$ cell strainer. Flow cytometric analysis was performed using FACSAria II (BD Biosciences, Franklin Lakes, NJ, USA), as described previously (17,22). ZsGreen was excited with the $488 \mathrm{~nm}$ laser and detected using the 530/30 nm emission filter. The fluorophore-conjugated antibodies used were as follows: Allophycocyanin (APC)-conjugated CD4 (cat. no. 561091; BD Biosciences), phycoerythrin (PE)-conjugated CD4 (cat. no. 100512; BioLegend, Inc., San Diego, CA, USA], 

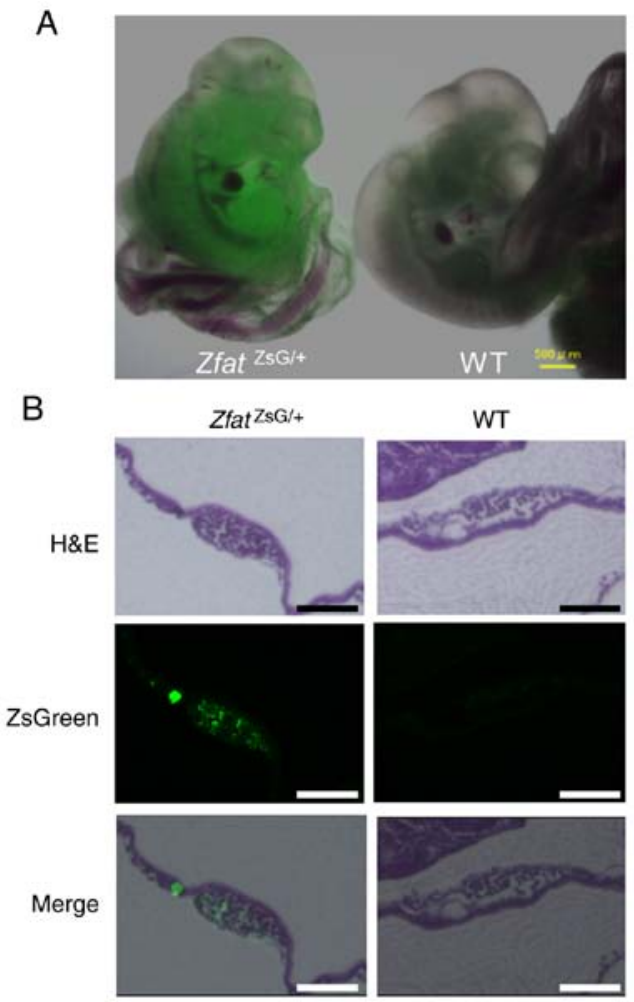

Figure 2. ZsGreen signals in $Z f a t^{\mathrm{ZsG} /+}$ embryos. (A) Merged images of ZsGreen signals and bright field in $\mathrm{Zfat}^{\mathrm{zs} /+}$ (left) and WT (right) embryos at E10. Scale bar, $500 \mu \mathrm{m}$. (B) $\mathrm{H} \& \mathrm{E}$ staining and ZsGreen signals in blood islands from $Z f a t^{Z \mathrm{SG} /+}$ (left) and WT (right) embryos at E9.5. Adjacent sections were used for H\&E staining or detection of ZsGreen signals. Merged images are presented. Scale bar, $100 \mu \mathrm{m}$. Data are representative of three independent experiments. E, embryonic day; H\&E, hematoxylin and eosin; WT, wild-type; Zfat, zinc finger and AT-hook domain containing.

APC-conjugated CD8 (cat. no. 100711; BioLegend, Inc.) PE/Cy7-conjugated CD8 (cat. no. 100722; BioLegend, Inc.), CD45R (B220) (cat. no. 25-0452-81; Thermo Fisher Scientific, Inc.), epithelial cell adhesion molecule (EpCAM) (cat. no. 17-5791-80; Thermo Fisher Scientific, Inc.), major histocompatibility complex (MHC)-II (cat. no. 107627; BioLegend, Inc.), c-kit (cat. no. 17-1171-81; Thermo Fisher Scientific, Inc.), CD71 (cat. no. 561937; BD Biosciences) and Ter119 (cat. no. 116221; BioLegend, Inc.). Data were analyzed using FlowJo $^{\mathrm{TM}} 10.2$ software (FlowJo, LLC, Ashland, OR, USA).

\section{Results}

Generation of Zfat-ZsGreen knock-in mice. To produce Zfat reporter $\left(Z f a t^{\mathrm{Zs} /+}\right)$ mice, ZsGreen, a bright green fluorescent protein derived from Zoanthus sp. reef coral, was used to replace exon 1 of the Zfat gene through homologous recombination (Fig. 1A-C). The pGKneo cassette was removed by crossing chimeric mice with a deleter strain expressing FLPe recombinase. After FLPe recombinase-mediated excision of the selection cassette, the knock-in allele, which contains the ZsGreen gene inserted in-frame with the Zfat ATG translation initiation site, carried transcriptional regulatory elements identical to those in the WT allele. As expected from the Zfat knock-out mice reported previously (15), intercrossing of $Z f a t^{\mathrm{ZsG} /+}$ mice never produces $Z f a t^{\mathrm{ZsG} / Z \mathrm{sG}}$ mice, whereas heterozygous knock-in mice were born and indistinguishable from WT mice.

To confirm the validity of the reporter system, ZsGreen signals were examined in E10 embryos using fluorescence microscopy. No green fluorescence was detected in the WT embryos, whereas ZsGreen signals were observed in the $\mathrm{Zfat}^{\mathrm{zsG} / \mathrm{+}}$ embryos (Fig. 2A). Furthermore, histological analysis indicated that ZsGreen signals were observed in hematopoietic progenitor cells in the yolk sac blood islands from $\mathrm{Zfat} t^{\mathrm{ZsG} /+}$ embryos, but not in those from WT embryos, at E9.5 (Fig. 2B). These results are consistent with the results of our previous study, which demonstrated that Zfat is expressed in the embryo and yolk sac blood islands (15). These results collectively indicated that endogenous Zfat expression was precisely reflected by $\mathrm{ZsGreen} \mathrm{signals} \mathrm{in} \mathrm{Zfat}^{\mathrm{ZsG} /+}$ mice.

Zfat expression in TECs. Using flow cytometric analysis for ZsGreen, Zfat expression was evaluated in immune cells from the spleen and thymus of $Z f a t^{\mathrm{ZSG} /+}$ mice. The majority of splenocytes from $\mathrm{Zfat}^{\mathrm{ZSG} / \mathrm{+}}$ mice exhibited $\mathrm{ZsGreen}$ signals that were higher than those from WT mice (Fig. 3A). ZsGreen ${ }^{+}$ cells were observed in $\mathrm{CD}^{+} \mathrm{T}, \mathrm{CD} 8^{+} \mathrm{T}$ and $\mathrm{B} 220^{+}$cells from $\mathrm{Zfat}^{\mathrm{ZsG} /+}$ spleen tissues (Fig. 3B). These results are consistent with the results of our previous study, which conducted immunoblotting analysis using the anti-Zfat antibody and detected high Zfat expression in these cell populations (3). In addition, thymocytes from $\mathrm{Zfat}^{\mathrm{ZsG} /+}$ mice exhibited high $\mathrm{ZsGreen}$ signals (Fig. 3A). ZsGreen ${ }^{+}$cells were observed not only in $\mathrm{CD} 4^{+} \mathrm{CD}^{+} \mathrm{DP}, \mathrm{CD} 4^{+} \mathrm{CD} 8$ single-positive and $\mathrm{CD} 4{ }^{-} \mathrm{CD} 8^{+}$ single-positive cells but also in $\mathrm{CD}^{-} \mathrm{CD} 8^{-}$double-negative (DN) cells (Fig. 3C). To address whether ZsGreen signals in the DN cell population are derived from T-cell progenitor cells or non-T-lineage cells in the thymus, ZsGreen signals were examined in TECs, which are essential for the establishment of central immunological tolerance by presenting self-antigens. Thymocytes were stained with EpCAM or MHC-II, both of which are known to be markers of TECs $(23,24)$. Notably, ZsGreen signals were identified in $\mathrm{EpCAM}^{+}$and $\mathrm{MHC}-\mathrm{II}^{+}$ cells in the DN cell population from $\mathrm{Zfat}^{\mathrm{Z \textrm {SG } /} /}$ thymus (Fig. 3D). These results suggested that Zfat serves particular roles in thymic T-cell development through the regulation of TECs as well as T-lineage cells.

Zfat expression in definitive erythroid progenitor cells. Our previous study reported that Zfat serves a key role in primitive erythropoiesis (15); however, its involvement in the regulation of definitive erythropoiesis remains to be determined. Therefore, the present study examined ZsGreen signals in the fetal liver from $Z f_{a t}{ }^{\mathrm{SG} /+}$ embryos at E12.5, where definitive erythropoiesis takes place. As definitive erythroid progenitor cells are known to express c-kit (25), the association between ZsGreen signals and c-kit expression was analyzed using flow cytometry. c-kit ${ }^{+}$cells in the fetal liver from $\mathrm{Zfat}^{\mathrm{ZSG} /+}$ embryos exhibited higher ZsGreen signals than those from WT embryos (Fig. 4A). Conversely, ZsGreen ${ }^{+}$cells were rarely detected in c-kit cells in the $Z f^{-} t^{\mathrm{ZsG} /+}$ fetal liver (Fig. 4A). Subsequently, ZsGreen signals were analyzed during the maturation of erythroid progenitor cells in definitive erythropoiesis in the fetal liver. Fetal liver cells in $\mathrm{Zfat}{ }^{\mathrm{ZsG} /+}$ embryos were stained with CD71 and Ter119, were analyzed by flow cytometry and 
A

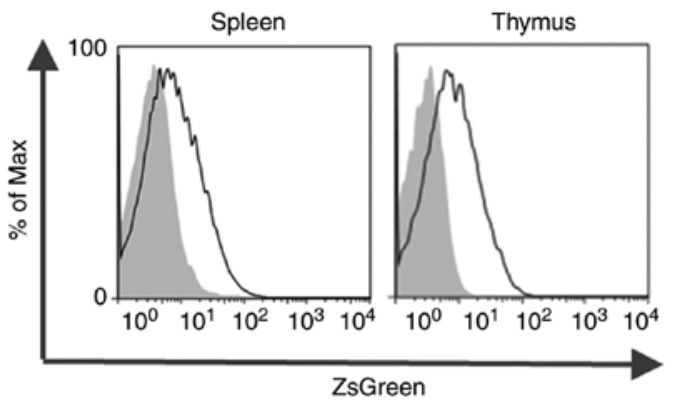

B

$\mathrm{CD}^{+}{ }^{+}$
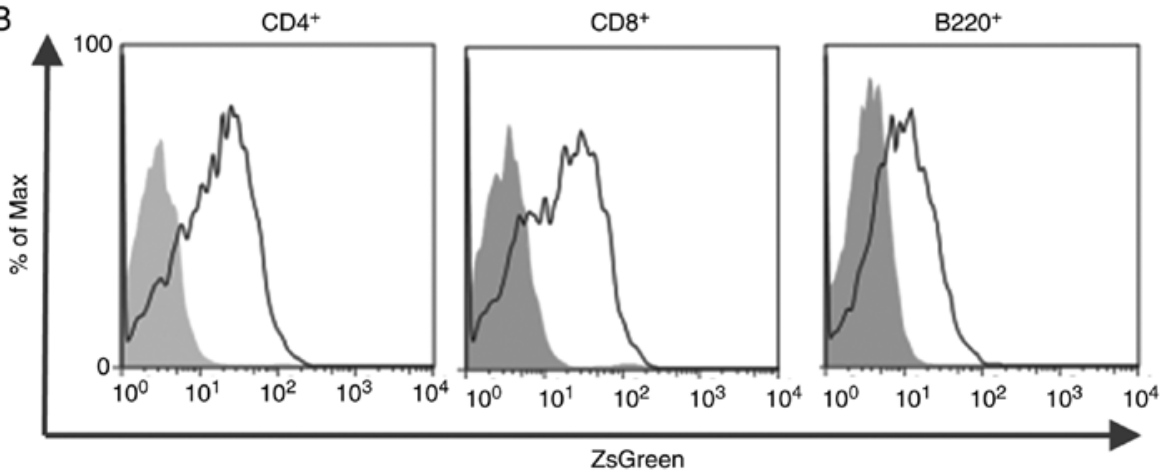

C

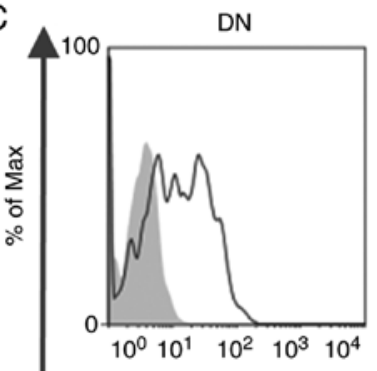

DP

ZsGreen
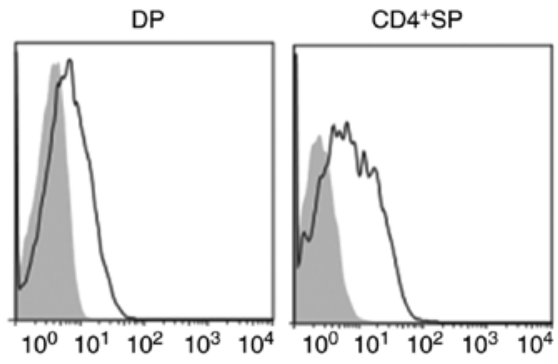

$\mathrm{CD}^{+} \mathrm{SP}$

ZsGreen

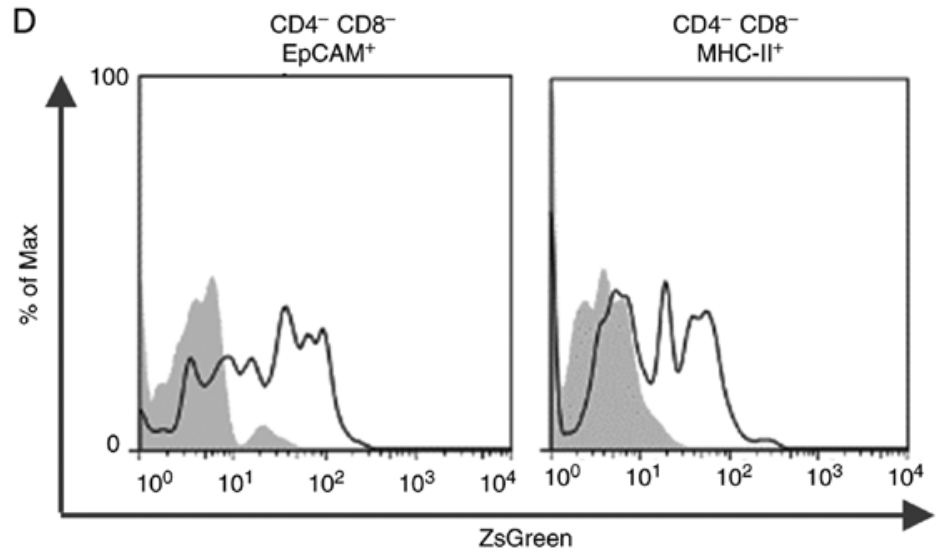

Figure 3. ZsGreen signals in splenocytes and thymocytes. (A) Flow cytometric analysis of ZsGreen in splenocytes or thymocytes isolated from 4-8-week-old

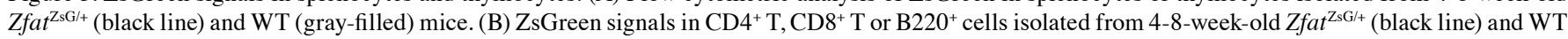
(gray-filled) spleen. (C) ZsGreen signals in CD4 CD8- DN, CD4 ${ }^{+} \mathrm{CD} 8^{+} \mathrm{DP}$, CD4 ${ }^{+} \mathrm{CD} 8-\mathrm{SP}$ or CD4 ${ }^{-} \mathrm{CD} 8^{+} \mathrm{SP}$ cells isolated from 4-8-week-old $\mathrm{Zfat} t^{\mathrm{ZG} / /+}$ (black

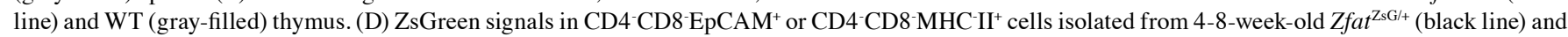
WT (gray-filled) thymus. Data are representative of three independent experiments. CD, cluster of differentiation; DN, double negative; DP, double positive; EpCAM, epithelial cell adhesion molecule; MHC, major histocompatibility complex; SP, single positive; WT, wild-type; Zfat, zinc finger and AT-hook domain containing.

were classified into P1 (CD71Ter119 $\left.{ }^{\text {low }}\right)$, P2 (CD71+Ter119 $\left.{ }^{\text {low }}\right)$, P3 (CD71+Ter119 $\left.{ }^{\text {mid }}\right)$ and P4 (CD71+Ter119 $\left.{ }^{\text {high }}\right)$ over the course of the maturation of erythroid progenitor cells (Fig. 4B). The proportion of $\mathrm{ZsGreen}{ }^{+}$cells was highest in the $\mathrm{P} 1$ cell population, and it was also high in the P2 cell population (Fig. 4C).
ZsGreen ${ }^{+}$cells were hardly detected in $\mathrm{P} 3$ and P4 populations in the $Z f a t^{\mathrm{ZSG} / 4}$ fetal liver, indicating that the expression levels of Zfat gradually decreased during the progression of erythroid maturation. Furthermore, the majority of c-kit ${ }^{+}$cells in the P1 population from the $Z f a t^{\mathrm{ZsG} /+}$ fetal liver expressed 

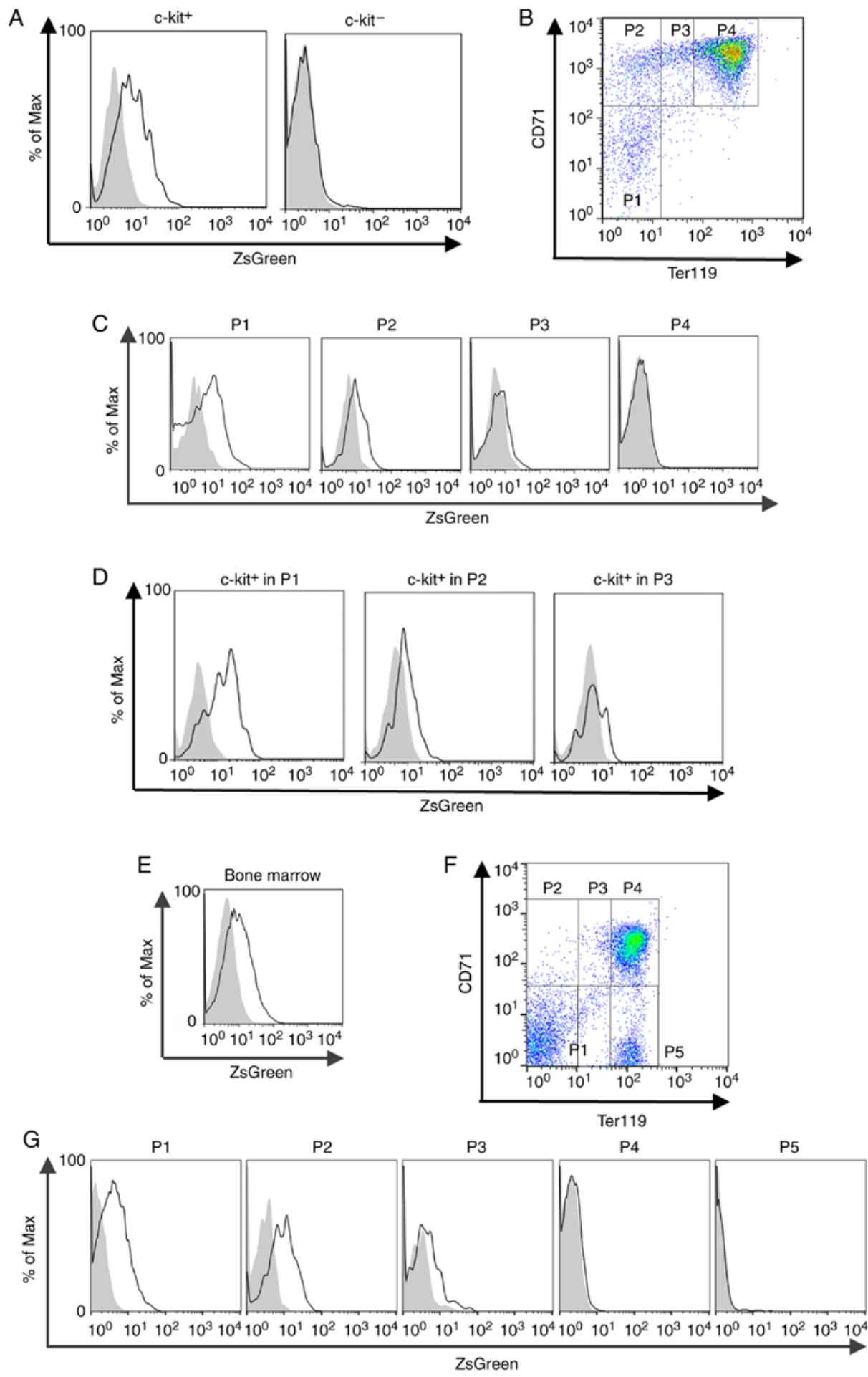

Figure 4. ZsGreen signals in erythroid progenitor cells in the fetal liver and adult bone marrow. (A) ZsGreen signals in c-kit ${ }^{+}$or c-kit cells from the Zfat ${ }^{\mathrm{ZsG} /+}$ (black line) and WT (gray-filled) fetal liver at E12.5. (B) Definition of stages during erythroid maturation in the fetal liver at E12.5. Fetal liver cells from $\mathrm{Zfat}^{\mathrm{ZsG} /+}$ embryos were stained with CD71 and Ter119, and analyzed by flow cytometry. P1, CD71-Ter119 $9^{\text {low }} ; \mathrm{P} 2, \mathrm{CD} 71^{+}$Ter119 $9^{\text {low }} ; \mathrm{P} 3, \mathrm{CD} 71^{+}$Ter119 ${ }^{\mathrm{mid}} ;$ and P4, CD71 ${ }^{+}$Ter119 ${ }^{\text {high }}$. (C) ZsGreen signals in P1-P4 cells from the Zfat ${ }^{\text {ZSG/+ }}$ (black line) and WT (gray-filled) fetal liver at E12.5. (D) ZsGreen signals in c-kit ${ }^{+}$cells in the P1-P3 population from the $\mathrm{ffat}_{\mathrm{Z \textrm {SG }} /+}$ (black line) and WT (gray-filled) fetal liver at E12.5. (E) ZsGreen signals in the bone marrow cells isolated from 4-week-old $\mathrm{fat}^{\mathrm{ZSG} /+}$ (black line) and WT (gray-filled) mice. (F) Definition of stages during erythroid maturation in the adult bone marrow. Bone marrow cells

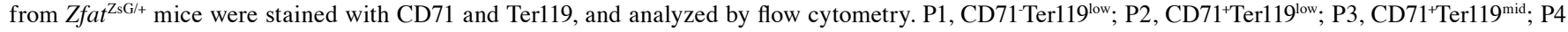
CD71 Ter119 ${ }^{\text {high }}$; and P5, CD71 Ter119 ${ }^{\text {high }}$. (G) ZsGreen signals in P1-P5 cells from the Zfat ${ }^{\text {ZSG/t+ }}$ (black line) and WT (gray-filled) bone marrow. Data are representative of three independent experiments. CD, cluster of differentiation; E, embryonic day; WT, wild-type; Zfat, zinc finger and AT-hook domain containing.

ZsGreen, and there were also substantial numbers of ZsGreen ${ }^{+}$ cells among the c-kit ${ }^{+} \mathrm{P} 2$ cells (Fig. 4D), indicating that Zfat is expressed in c-kit ${ }^{+}$definitive erythroid progenitor cells, particularly at the P1 and P2 stages.
Notably, bone marrow in adult $Z f a t^{\mathrm{ZSG} /+}$ mice contained substantial numbers of ZsGreen ${ }^{+}$cells (Fig. 4E). Similar to the cells in fetal liver, the cells in $\mathrm{Zfat}^{\mathrm{Z} \mathrm{sG} /+}$ bone marrow were stained with CD71 and Ter119, and were classified according 

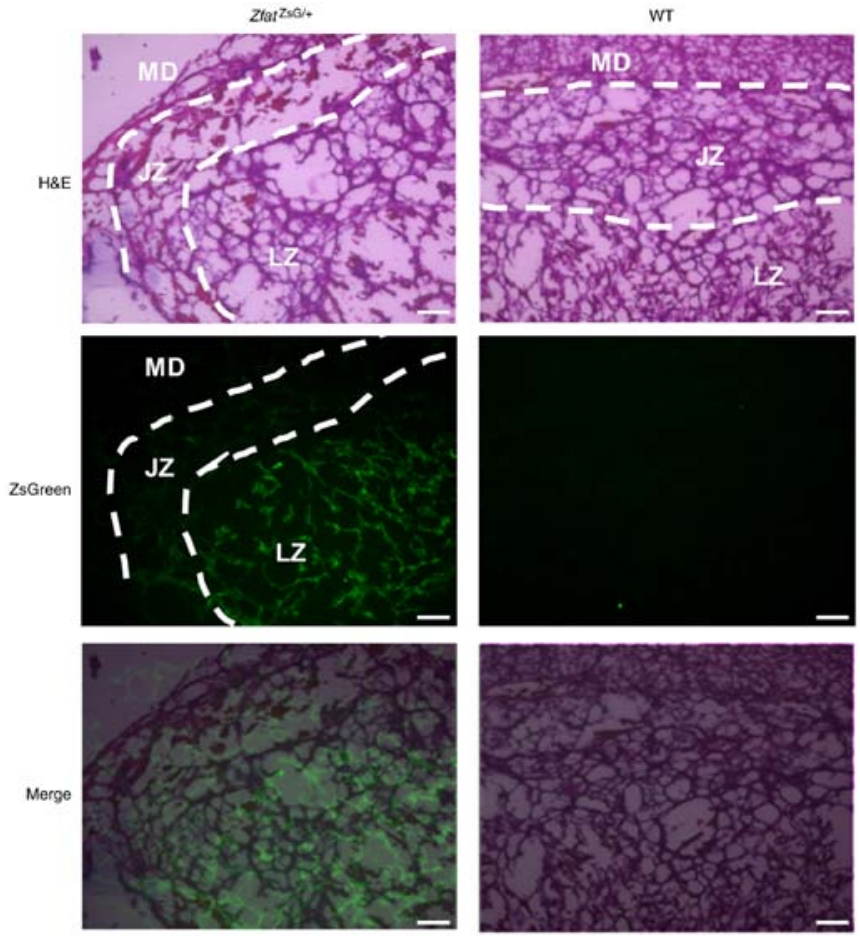

Figure 5. ZsGreen signals in the LZ in the placenta. H\&E staining and ZsGreen signals were detected in adjacent sections from $\mathrm{Zfat}^{\mathrm{ZsG} /+}$ (left) and WT (right) placenta at embryonic day 13.5. Merged images are presented. Scale bar, $100 \mu \mathrm{m}$. H\&E, hematoxylin and eosin; JZ, junctional zone; LZ, labyrinth zone; MD, maternal decidua; WT, wild-type; Zfat, zinc finger and AT-hook domain containing.

to the course of erythroid progenitor cell maturation (Fig. 4F). The proportion of $\mathrm{ZsGreen}^{+}$cells was the highest in the P1 and P2 cell populations, and a few cells in the P3 population exhibited modest ZsGreen signals (Fig. 4G). Conversely, $\mathrm{ZsGreen}^{+}$cells were rarely detected in P4 and P5 populations in the $Z f a t^{Z s G /+}$ bone marrow (Fig. 4G). These results suggested that Zfat may serve particular roles during the early stage of definitive erythropoiesis in the fetal liver and adult bone marrow.

Zfat expression in the placenta and nervous tissue. Our previous study reported a defect in the development of spongiotrophoblast layers in the $Z \mathrm{fat}^{-/}$placenta (15). To address whether Zfat is expressed in the placenta, histological analysis was performed on E13.5 placenta, and ZsGreen signals were detected in the labyrinth zone in the $Z \mathrm{fat}^{\mathrm{ZsG} /+}$ placenta (Fig. 5). Due to impaired development in $\mathrm{Zfat}^{-/-}$placenta, these findings indicated that Zfat may have a critical role in this organ.

To the best of our knowledge, the expression and functions of Zfat in nervous tissue are unknown. Flow cytometric analysis of brain tissues from adult $Z \mathrm{fat}^{\mathrm{ZsG} /+}$ mice indicated that the cerebrum and cerebellum contained $\mathrm{ZsGreen}^{+}$cells (Fig. 6A). Histological analysis revealed that $\mathrm{ZsGreen}^{+}$cells were specifically observed in the pyramidal cell layer in the hippocampal CA1 region and the Purkinje cell layer in the cerebellum of $\mathrm{Zfat}^{\mathrm{ZsG} /+}$ brain (Fig. $6 \mathrm{~B}$ and $\mathrm{C}$ ), thus suggesting novel functions of $Z$ fat in nervous tissue.

Finally, Zfat expression was evaluated in various tissues of $Z \mathrm{fat}^{\mathrm{ZsG} /+}$ mice using flow cytometric analysis of ZsGreen.
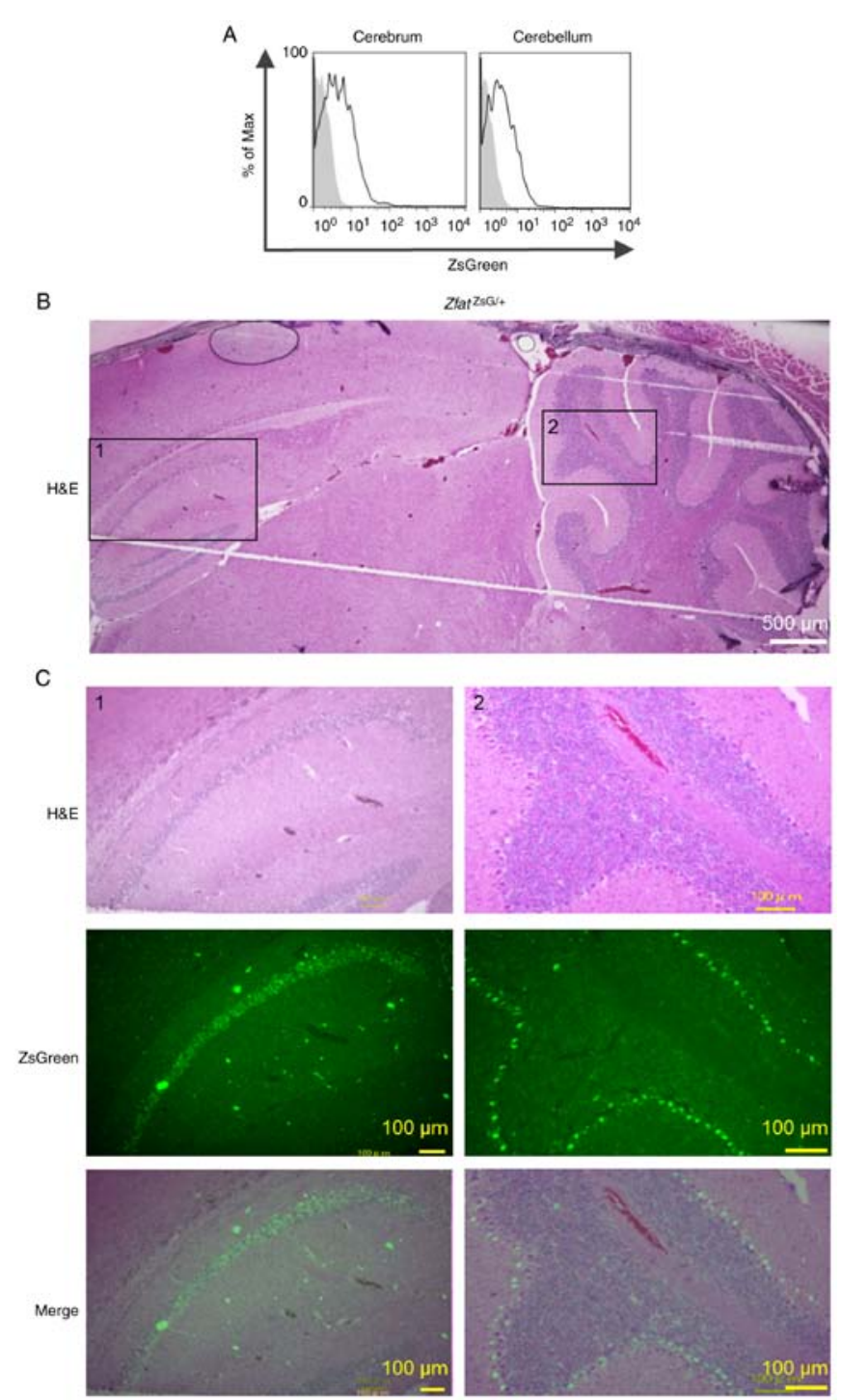

Figure 6. ZsGreen signals in nervous tissues. (A) Flow cytometric analysis of ZsGreen in cells isolated from the cerebrum and cerebellum of 4-8-week-old $\mathrm{Zfat}^{\mathrm{ZsG} /+}$ (black line) and wild-type (gray-filled) brain. (B) H\&E staining of sections from 4-8-week-old $\mathrm{Zfat}^{\mathrm{ZsG} /+}$ brain. The areas enclosed by black lines indicate the CA1 region (\#1) and the Purkinje cell layer (\#2). (C) H\&E staining and $\mathrm{ZsGreen}$ signal detection in adjacent sections from $\mathrm{Zfat}^{\mathrm{ZsG} /+}$ brain. Enlarged images in the areas enclosed by black lines in panel B are shown. Merged images are presented. Scale bars, $500 \mu \mathrm{m}$ (top panel) and $100 \mu \mathrm{m}$ (enlarged images). Data are representative of three independent experiments. H\&E, hematoxylin and eosin; Zfat, zinc finger and AT-hook domain containing.

Among the tissues examined in this study, cells from the testes of $Z f a t^{\mathrm{ZsG} /+}$ mice exhibited the highest intensity of ZsGreen signals (Fig. 7). ZsGreen signals were also observed in the majority of cells from the retina of $Z f a t^{\mathrm{ZsG} /+}$ mice (Fig. 7). Furthermore, cells from the lungs of $Z f t^{\mathrm{ZsG} /+}$ mice exhibited moderate ZsGreen signals, whereas ZsGreen ${ }^{+}$cells were rarely detected in the $Z \mathrm{fat}^{\mathrm{ZsG} /+}$ liver (Fig. 7). These results suggested that Zfat serves particular roles in the tissues where ZsGreen signals were detected.

\section{Discussion}

The nuclear protein Zfat is a transcriptional regulator that harbors DNA binding domains, including AT-hook and 


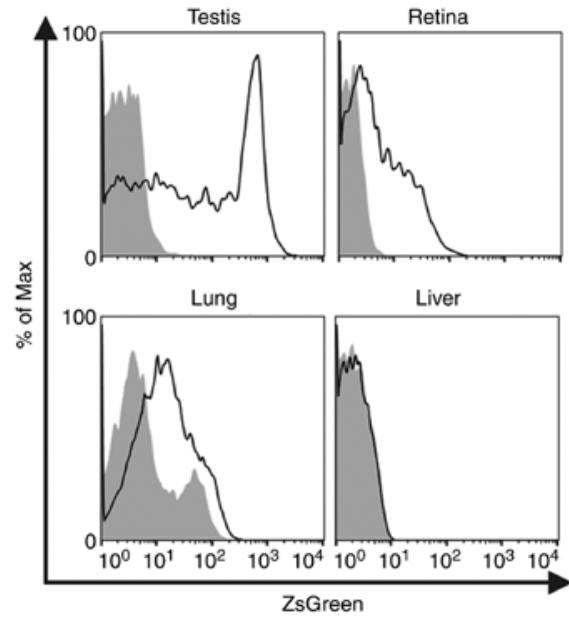

Figure 7. ZsGreen signals in various tissues. Flow cytometric analysis of ZsGreen in cells isolated from various tissues from 4-10-week-old $\mathrm{Zfat}^{\mathrm{ZGG} /+}$ (black line) and wild-type (gray-filled) mice. Data are representative of three independent experiments. zinc finger and AT-hook domain containing.

zinc-finger domains $(2,4)$. Our previous study demonstrated that Zfat has critical roles in thymic T-cell development and peripheral T-cell homeostasis $(16,26,27)$. In addition, accumulating evidence has suggested that $\mathrm{Zfat}$ has critical functions in non-immune cells $(27,28)$. However, the precise expression pattern of Zfat remains to be determined.

Our previous study reported that $Z$ fat gene deletion in mice results in impaired differentiation of hematopoietic progenitor cells in the blood islands, indicating critical roles of Zfat in primitive erythropoiesis (15). The present study used $\mathrm{Zfat}^{\mathrm{ZsG} /+}$ mice and detected Zfat-expressing cells during definitive erythroid maturation in the fetal liver and adult bone marrow. The majority of cells in the P1 cell population in these tissues exhibited ZsGreen signals, whereas the proportion of $\mathrm{ZsGreen}^{+}$cells gradually decreased during the progression of erythroid maturation. These results indicated that Zfat expression may be restricted to the early stage of definitive erythropoiesis, thus suggesting that Zfat is involved in the differentiation of erythroid progenitors in both fetal and postnatal definitive erythropoiesis. Because $\mathrm{Zfat}^{-1-}$ mice exhibit embryonic lethality by E8.5 (15), the roles of Zfat in definitive erythropoiesis remain to be elucidated. Therefore, conditional or inducible Zfat gene knock-out mice may be useful in elucidating the roles of Zfat in definitive erythropoiesis. Further studies are required to obtain a comprehensive understanding of the roles of Zfat in definitive erythropoiesis.

Zfat gene ablation in thymic $\mathrm{T}$ cells in $\mathrm{Zfat} \mathrm{t}^{\mathrm{f} / \mathrm{f}}-\mathrm{LckCre}$ mice induces severe defects in T-cell differentiation in the thymus, accompanied by impaired positive selection and excessive apoptosis, thus indicating the intrinsic roles of Zfat in thymic T-cell development $(16,17)$. In the present study, in $Z f a t^{\mathrm{ZsG} /+}$ mice, Zfat was expressed in TECs as well as in thymic T-lineage cells. TECs generate the microenvironment required for T-cell development within the thymus. Zfat expression in TECs suggests that Zfat may have roles in thymic T-cell development through the functional regulation of TECs, particularly antigen presentation to $\mathrm{T}$ cells.
The present study further identified novel tissues and cells that express Zfat using $Z f a t^{\mathrm{ZsG} /+}$ mice through a combination of histological and flow cytometric analyses. ZsGreen signals were detected in particular tissues, including the labyrinth zone in the placenta, the pyramidal cell layer in the hippocampal CA1 region and the Purkinje cell layer in the cerebellum, suggesting specific roles of Zfat in these tissues.

In conclusion, the present study established Zfat-ZsGreen knock-in mice to elucidate the expression and functions of Zfat during embryonic development and in adult tissues. Using this reporter mouse system, the results demonstrated that Zfat was expressed in TECs, definitive erythroid progenitor cells in the fetal liver and bone marrow, the labyrinth zone in the placenta and in nervous tissues, thus suggesting its novel functions in these cells and tissues. The $Z f a t^{\mathrm{ZsG} /+}$ reporter mouse may be considered a useful tool for elucidating the physiological roles and functions of Zfat.

\section{Acknowledgements}

The authors would like to thank Ms. Yumiko Hirose (Fukuoka University, Fukuoka, Japan) and Ms. Takami Danno (Fukuoka University) for their valuable technical assistance.

\section{Funding}

The present study was supported, in part, by grants from the Ministry of Education, Culture, Sport, Science and Technology of Japan.

\section{Availability of data and materials}

All data generated or analyzed during this study are included in this published article.

\section{Authors' contributions}

TT, SI, HM, YT and TO generated the knock-in mice. TT and MK performed the histological examinations. KD, HL and KN performed the flow cytometry experiments. All experiments were conducted by SS. The manuscript was written by TT, SI and SS. All authors read and approved the manuscript.

\section{Ethics approval and consent to participate}

All animal experiments were approved by the Animal Care and Use Committee of the National Center for Global Health and Medicine (NCGM) Research Institute (NCGM\#14032; Tokyo, Japan), and the Institutional Animal Care and Use Committee of Fukuoka University (Fukudai\#157; Fukuoka, Japan). The study was approved by the ethics committee of Fukuoka University (Fukudai\#372).

\section{Patient consent for publication}

Not applicable.

\section{Competing interests}

The authors declare that they have no competing interests. 


\section{References}

1. Ishikura S, Tsunoda T, Nakabayashi K, Doi K, Koyanagi M, Hayashi K, Kawai T, Tanaka Y, Iwaihara Y, Luo H, et al: Molecular mechanisms of transcriptional regulation by the nuclear zinc-finger protein Zfat in T cells. Biochim Biophys Acta 1859: 1398-1410, 2016.

2. Tochio N, Umehara T, Nakabayashi K, Yoneyama M, Tsuda K, Shirouzu M, Koshiba S, Watanabe S, Kigawa T, Sasazuki T, et al: Solution structures of the DNA-binding domains of immune-related zinc-finger protein ZFAT. J Struct Funct Genom 16: 55-65, 2015.

3. Koyanagi M, Nakabayashi K, Fujimoto T, Gu N, Baba I, Takashima Y, Doi K, Harada H, Kato N, Sasazuki T and Shirasawa S: ZFAT expression in B and T lymphocytes and identification of ZFAT-regulated genes. Genomics 91: 451-457, 2008.

4. Shirasawa S, Harada H, Furugaki K, Akamizu T, Ishikawa N, Ito K, Ito K, Tamai H, Kuma K, Kubota S, et al: SNPs in the promoter of a B cell-specific antisense transcript, SAS-ZFAT, determine susceptibility to autoimmune thyroid disease. Hum Mol Genet 13: 2221-2231, 2004.

5. Comabella M, Craig DW, Morcillo-Suárez C, Río J, Navarro A, Fernández M, Martin R and Montalban X: Genome-wide scan of 500,000 single-nucleotide polymorphisms among responders and nonresponders to interferon beta therapy in multiple sclerosis. Arch Neurol 66: 972-978, 2009

6. Inoue N, Watanabe M, Yamada H, Takemura K, Hayashi F, Yamakawa N, Akahane M, Shimizuishi Y, Hidaka Y and Iwatani Y: Associations between autoimmune thyroid disease prognosis and functional polymorphisms of susceptibility genes, CTLA4, PTPN22, CD40, FCRL3, and ZFAT, previously revealed in genome-wide association studies. J Clin Immunol 32: 1243-1252, 2012.

7. Ji HY, Yang B, Zhang ZY, Ouyang J, Yang M, Zhang XF, Zhang WC, Su Y, Zhao KW, Xiao SJ, et al: A genome-wide association analysis for susceptibility of pigs to enterotoxigenic Escherichia coli F41. Animal 10: 1602-1608, 2016.

8. Sabatino G, Rigante L, Minella D, Novelli G, Della Pepa GM Esposito G, Albanese A, Maira G and Marchese E: Transcriptional profile characterization for the identification of peripheral blood biomarkers in patients with cerebral aneurysms. J Biol Regul Homeost Agents 27: 729-738, 2013.

9. Slavin TP, Feng T, Schnell A, Zhu X and Elston RC: Two-marker association tests yield new disease associations for coronary artery disease and hypertension. Hum Genet 130: 725-733, 2011.

10. Ramakrishna M, Williams LH, Boyle SE, Bearfoot JL, Sridhar A, Speed TP, Gorringe KL and Campbell IG: Identification of candidate growth promoting genes in ovarian cancer through integrated copy number and expression analysis. PLoS One 5: e9983, 2010.

11. Takeuchi F, Nabika T, Isono M, Katsuya T, Sugiyama $T$, Yamaguchi S, Kobayashi S, Yamori Y, Ogihara T and Kato N: Evaluation of genetic loci influencing adult height in the Japanese population. J Hum Genet 54: 749-752, 2009.

12. Cho YS, Go MJ, Kim YJ, Heo JY, Oh JH, Ban HJ, Yoon D, Lee MH, Kim DJ, Park M, et al: A large-scale genome-wide association study of Asian populations uncovers genetic factors influencing eight quantitative traits. Nat Genet 41: 527-534, 2009

13. Signer-Hasler H, Flury C, Haase B, Burger D, Simianer H, Leeb T and Rieder S: A genome-wide association study reveals loci influencing height and other conformation traits in horses. PLoS One 7: e37282, 2012.

14. Makvandi-Nejad S, Hoffman GE, Allen JJ, Chu E, Gu E, Chandler AM, Loredo AI, Bellone RR, Mezey JG, Brooks SA and Sutter NB: Four loci explain $83 \%$ of size variation in the horse. PLoS One 7: e39929, 2012.
15. Tsunoda T, Takashima Y, Tanaka Y, Fujimoto T, Doi K, Hirose Y, Koyanagi M, Yoshida Y, Okamura T, Kuroki M, et al: Immune-related zinc finger gene ZFAT is an essential transcriptional regulator for hematopoietic differentiation in blood islands. Proc Natl Acad Sci USA 107: 14199-14204, 2010.

16. Ishikura S, Ogawa M, Doi K, Matsuzaki H, Iwaihara Y, Tanaka Y, Tsunoda T, Hideshima H, Okamura T and Shirasawa S: Zfat-deficient $\mathrm{CD} 4^{+} \mathrm{CD} 8^{+}$double-positive thymocytes are susceptible to apoptosis with deregulated activation of p38 and JNK. J Cell Biochem 116: 149-157, 2015.

17. Ogawa M, Okamura T, Ishikura S, Doi K, Matsuzaki H, Tanaka Y, Ota T, Hayakawa K, Suzuki H, Tsunoda T, et al: Zfat-deficiency results in a loss of $\mathrm{CD} 3 \zeta$ phosphorylation with dysregulation of ERK and Egr activities leading to impaired positive selection. PLoS One 8: e76254, 2013.

18. Doi K, Fujimoto T, Okamura T, Ogawa M, Tanaka Y, Mototani Y, Goto M, Ota T, Matsuzaki H, Kuroki M, et al: ZFAT plays critical roles in peripheral $\mathrm{T}$ cell homeostasis and its $\mathrm{T}$ cell receptor-mediated response. Biochem Biophys Res Commun 425: 107-112, 2012

19. Ishikura S, Iwaihara Y, Tanaka Y, Luo H, Nishi K, Doi K, Koyanagi M, Okamura T, Tsunoda T and Shirasawa S: The nuclear zinc finger protein Zfat maintains FoxO1 protein levels in peripheral $\mathrm{T}$ cells by regulating the activities of autophagy and the Akt signaling pathway. J Biol Chem 291: 15282-15291, 2016.

20. Fujimoto T, Miyasaka K, Koyanagi M, Tsunoda T, Baba I, Doi K, Ohta M, Kato N, Sasazuki T and Shirasawa S: Altered energy homeostasis and resistance to diet-induced obesity in KRAP-deficient mice. PLoS One 4: e4240, 2009.

21. Kawamoto $\mathrm{T}$ and Kawamoto K: Preparation of thin frozen sections from nonfixed and undecalcified hard tissues using Kawamot's film method (2012). Methods Mol Biol 1130: 149-164, 2014.

22. Nishi K, Iwaihara Y, Tsunoda T, Doi K, Sakata T, Shirasawa S and Ishikura S: ROS-induced cleavage of NHLRC2 by caspase- 8 leads to apoptotic cell death in the HCT116 human colon cancer cell line. Cell Death Dis 8: 3218, 2017.

23. Yang SJ, Ahn S, Park CS, Holmes KL, Westrup J, Chang CH and Kim MG: The quantitative assessment of MHC II on thymic epithelium: Implications in cortical thymocyte development. Int Immunol 18: 729-739, 2006.

24. Gray DH, Chidgey AP and Boyd RL: Analysis of thymic stromal cell populations using flow cytometry. J Immunol Methods 260: $15-28,2002$.

25. Fraser ST, Isern $\mathrm{J}$ and Baron MH: Maturation and enucleation of primitive erythroblasts during mouse embryogenesis is accompanied by changes in cell-surface antigen expression. Blood 109: 343-352, 2007.

26. Iwaihara Y, Ishikura S, Doi K, Tsunoda T, Fujimoto T, Okamura T and Shirasawa S: Marked reduction in FoxO1 protein by its enhanced proteasomal degradation in Zfat-deficient peripheral T-cells. Anticancer Res 35: 4419-4423, 2015.

27. Doi K, Ishikura S and Shirasawa S: The roles of ZFAT in thymocyte differentiation and homeostasis of peripheral naive T-cells. Anticancer Res 34: 4489-4495, 2014.

28. Tsunoda T and Shirasawa S: Roles of ZFAT in haematopoiesis, angiogenesis and cancer development. Anticancer Res 33: 2833-2837, 2013.

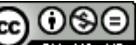

This work is licensed under a Creative Commons Attribution-NonCommercial-NoDerivatives 4.0 International (CC BY-NC-ND 4.0) License. 